\title{
Jin-hui Wang \\ Demonstration Project of Safe and Efficient Mining Operations in Extra-thick Coal Seam
}

\begin{abstract}
Mineable coal reserves in thick and extra-thick seams account for $44 \%$ of the total deposit in China. Fullymechanized top-coal caving technology is a new mining method of safe and efficient underground operations in extra-thick seams in China. The development of fullymechanized top-coal caving technology in China, which was successfully applied in Face 8105 in Tashan Coal Mine, Datong, Shanxi, China, is analyzed in this paper. Studies on movement pattern of top-coal and roof from fully-mechanized top caving face in 14-20 m extra-thick seams have been carried out. A series of key technologies were successfully developed, including strata control technology, equipment for high-efficient and high-recovery top caving operations, and safety guarantee technology for low gas occurrence and high gas emission. As a result, the fully-mechanized top-coal caving Face 8105, with large mining height in Tashan Coal Mine, has achieved a recovery rate of $88.9 \%$ and an average equipment operation rate of $92.1 \%$. With coal production of $10.84 \mathrm{Mt}$ in 2011, the demonstration project is a technology and equipment breakthrough for fully-mechanized top-coal caving face in extra-thick coal seams with large mining height.
\end{abstract}

Keywords: demonstration project, extra-thick coal seam, large mining height, fully-mechanized top-coal caving recovery rate, strata control, safety guarantee

\section{Development of fully-mechanized top-coal caving technology}

China has approximately 2,200 Bt of proven coal resources, including $1,540 \mathrm{Bt}$ of basic coal resources for coal mining construction. Coal resources in thick coal seams account for $44 \%$ of the basic coal resources. Annual

Manuscript received April 20, 2016; accepted August 10, 2016

Jin-hui Wang $(\bowtie)$

China Coal Technology \& Engineering Group Corporation, Beijing 100013, China

Email: duxiaojun2011@126.com underground coal production from thick coal seams exceeds $45 \%$ of that of the national total. China has done numerous tests and researches on mechanized coal mining methods, and a series of mining technology systems for thick and extra-thick coal seams have been gradually developed. There have been three major mechanical mining methods for thick coal seams, including fullymechanized long wall top-coal caving mining method (hereinafter referred to as LTCC mining method), fullymechanized sub-level coal mining method, and fullymechanized mining method with large mining height. For extra-thick coal seams over $7 \mathrm{~m}$, the top caving mining method is the first choice. For coal seams with thicknesses of 7-14 $\mathrm{m}$, the top caving mining method can be applied because the technologies are well established and the equipment are manufactured. Over the years, to achieve safe and efficient coal extraction in extra-thick coal seams with thicknesses of 14-20 m, China has developed a complete set of technologies and equipment for fullymechanized long wall top-coal caving face with large mining height (hereinafter referred to as LLTCC). The technologies and equipment developed have been successfully applied in Tashan Coal Mine of Datong Shanxi, China. The LLTCC face achieved coal production of 10Mt/ a in extra-thick coal seam, a significant breakthrough in technology and equipment for extra-thick seam mining (Wang, 2006, 2013).

The development of top-coal caving technology has a long history. In the early twentieth century, the top-coal caving mining method was applied to steep seams in France, Spain and former Yugoslavia. Because mechanical level was low in mining industry at that time, the method was actually an alternative of the high caving mining method, which was only used as a special choice under complicated geological conditions. Its efficiency was low and safety was not ensured. With the progress of hydraulic support technology, the fully-mechanized top-coal caving technology was improved and successfully applied in some countries. However, since no technology could solve the bottleneck of top-coal caving technology in difficult geological conditions, there was no clear progress in 
applying the top-coal caving technology in the abovementioned countries. With the recent development in China, the top-coal caving technology and equipment have been widely applied with excellent results. Additionally, the technology has been promoted on the international market. Russia, Turkey, India and Australia have imported the technology and equipment from China, and have done successful applications in underground coal mines respectively.

The top-coal caving mining technology is being developed very fast in China and has been used in some projects. Its significant economic and technological benefits have impressed the world. In China, the top-coal caving mining method refers to the fully-mechanized long wall top-coal caving mining method. In this method, a long wall panel is placed at the bottom of the thick coal seam. At the same time, the remaining coal above the long wall face are fractured by ground stress and strain (manually fractured in some special cases), and caved through the sliding window at the support canopies into the rear scraper conveyor, and then transported out of the face. There are four stages for the development of LTCC technology in China (Mao \& Yao, 2010; Qian \& Shi, 2003; Wang, 2010).

Stage I is the initial phase (1982-1990). The LTCC technology was introduced to China in 1982. The first industrial test of the technology was carried out in a slightly inclined seam of North Mining Area 3 in Puhe Coal Mine, Shenyang Mining Bureau, Liaoning, China in 1984. Due to support design failure, improper equipment matching and insufficient experiences in production management, the trial was not successful. However, subsequent tests in steep inclined coal seams in Coal Mine 2 of Yaojie Mining Bureau, Meihekou Coal Mine of Liaoyuan Mining Bureau, and Liudaowan Coal Mine of Urumqi Mining Bureau were all successful. In 1990, tests on technology in slightly inclined coal seams were done in North-eastern China and Pingdingshan of Henan, but there were no breakthrough. In the second half of 1990, the LTCC Face 8603 in Coal Mine 1 of Yangquan Mining Bureau in Shanxi produced $140,000 \mathrm{t} / \mathrm{m}$, doubling the production from a sub-level face, and coal recovery rate exceeded $80 \%$. The dip of the LTCC face was $3^{\circ}-7^{\circ}$, the thickness was $6 \mathrm{~m}$ and the face was $120 \mathrm{~m}$ wide. The test in Yangquan explored a way to achieve high production, high efficiency from the LTCC face, demonstrating the potential of LTCC technology and laying a solid foundation for developing the LTCC technology. The feasibility of this technology to achieve high production and high efficiency has been proven at this stage.

Stage II is the developing phase (1990-1995). The key achievement at this stage was the LTCC Face in Xinglongzhuang Coal Mine of Yanzhou Mining Bureau in Shandong, China, with a high production of $3 \mathrm{Mt} / \mathrm{a}$. The breakthrough for LTCC technology at "three soft" coal seams (soft roof, soft coal and soft floor seam), "large dip" coal seams (approximately $30^{\circ}$ ), and "high gassy" coal seams was made, enabling widespread application of the technology all over China. At this stage, the LTCC technology developed quickly. Besides, the research and development were very active on strata control, supportstrata relationship, cavability of top-coals, and methods of top-coal caving, bringing about various theories and practices. United research and collective development became popular national wide.

Stage III is a phase of technical maturation and promotion (1995-2005). With the proven huge technical and economic advantages, LTCC technology has drawn great attention from mining companies in China. Overcoming key technical difficulties, LTCC technology was widely and quickly applied in the coal mining industry in China. In 1995, LTCC technology was selected as one of five key technologies for further research and promotion during the Ninth Five-year Plan (1996-2000) by the Ministry of Coal Industry of China. Several major technical issues associated with the LTCC mining method were regarded as key research topics. In addition, in 1997, National Natural Science Foundation of China provided funding to support the key research project of "Basic study on full seam cutting in thick coal seams." Various achievements were made at this stage. Coal mines with favorable geological conditions, such as simple geological conditions, large coal reserves, fewer natural hazards, 6-9 m coal seams, and medium hard coals, substantially increased the annual coal production from the LTCC faces. For instance, in 1997, coal production from the LTCC Face in Dongtan Mine of Yanzhou, Shandong, China, was 4.1 Mt/a and $208 \mathrm{t}$ per man. In 1998, at the same face, coal production was $5.4 \mathrm{Mt} / \mathrm{a}$, and work efficiency $235 \mathrm{t}$ per man, which was regarded as advanced world level then. At this stage, the LTCC technology was developed to mine coal with more difficult seams, such as soft roof, soft seam and soft floor, hard roof and hard seam, steep inclination, high gassy, spontaneous combustion-prone, and relative thinner thick seams. Various practical technologies were developed accordingly.

During the Tenth Five-year Plan (2001-2005), a project named "Research and experiment on $6 \mathrm{Mt} / \mathrm{a}$ LTCC technology and equipment" was completed in Yanzhou, Shandong, China. The project made possible a LTCC Face production higher than $6 \mathrm{Mt}$ for six consequent years, a new level of LTCC technology in China.

Stage IV is an innovating phase (2005-present). In 2005, when studying on safe and efficient mining technologies for high gassy extra-thick coal seams, experts carried out various analysis on reasons why higher production was ceased from high gassy LTCC faces. The study on feasibility of further increasing cutting height was carried out with the LTCC technology in extra-thick seams. In 2006, Li, Liu, and Zeng (2006) presented some characteristics and potentials of designing top caving hydraulic support with large mining heights. In terms of equipment capacities, Lu, Zhao, Xu, and Xue (2006) conducted 
studies on a complete set of mining equipment with a cutting height of $3.5 \mathrm{~m}$. In 2008, the Ministry of Science and Technology of China approved the major project "Research on LTCC technology and equipment with large mining height" as part of the National High-tech R \& D Program. Targeted at coal seams with thickness of 14-20 m, the project developed a large cutting height LTCC mining method (LLTCC mining method), a complete set of mining equipment, roadway drivage and supporting technology and equipment, and mine safety security technology and equipment (Wang, 2013). In 2011, the technologies and equipment developed were tested in Face 8105 of Tashan Coal Mine in Datong, Shanxi, China, with production up to $1.0849 \mathrm{Mt} / \mathrm{a}$. The success of this project marked a new level of LLTCC technology and equipment for extra-thick coal seams in China. The paper presents the industrial test at the fully-mechanized top caving Face 8105 with large mining height in Tashan Coal Mine, Tatong, Shanxi, China. The development of key technologies for fully-mechanized top-coal caving mining method in extra-thick coal seams with large mining height is also analyzed.

\section{Coal mine with the industrial test}

The buried depth of Coal Seam 3-5 in Tashan Coal Mine ranges from $347 \mathrm{~m}$ to $447 \mathrm{~m}$, with an average thickness of $16.8 \mathrm{~m}$ and the maximum of $20 \mathrm{~m}$, and an average inclination of $4^{\circ}$. The protodyakonov coefficient $\mathrm{F}$ of the seams ranges from 2.7 to 13.7 . The seams have 4-14 rock partings, and their lithologies consist of gray brown kaolinite, kaolinitic mudstone, gray and black carbonaceous mudstone, sandy mudstone, and dark gray siltstone locally.

The top of Seam 3-5 has a false roof of gray black carbonaceous mudstone with the thickness of $0.33 \mathrm{~m}$. The top of the immediate roof is consisted of brown gray kaolinitic mudstone, magmatic rock and Seam 2. The middle of the immediate roof is composed of shed coal and silicified coal. The bottom is consisted of gray black carbonaceous mudstone, kaolinite and magmatic rock. The thickness of the immediate roof is $2.4-6.3 \mathrm{~m}$. From the top to the bottom, the main roof is consisted of Seam 4, magmatic rock, silicified coal, siltstone, fine sandstone, kaolinitic mudstone and sandy mudstone. The thickness of the main roof varies from $11.31 \mathrm{~m}$ to $27.36 \mathrm{~m}$. The immediate floor is consisted of gray brown kaolinitic mudstone and sandy mudstone, with loose coal particles. The main floor is composed of dark gray siltstone with fine sandstone locally. The length of the LLTCC Face 8105 is $207 \mathrm{~m}$. The comprehensive histogram of coal rock strata is shown in Figure 1.

The face is affected by igneous rock. Thus, there are some metamorphism and silicification in Seam 3-5. The seam structure is complex. The coal with metamorphism and silicification is hard, broken with well-developed cleats. Mixed coal is loose and fragile. The lower part of the seam is stable and hard, in the shape of a sandwich, shown in Figure 2.

The relative gas emission from Seam 3-5 in Tashan Coal Mine is $1.95 \mathrm{~m}^{3} / \mathrm{t}$, which is classified as a low gassy mine. However, coal dust in the mine could cause dust explosion, as the explosion index is up to $37 \%$. The period of spontaneous combustion is 68 days. The mine has no high temperature area. The geothermal gradient is $2.41^{\circ} \mathrm{C} / 100 \mathrm{~m}$.

\section{Strata control technology for LLTCC Face}

\subsection{Fractural characteristics of top-coals and roof at a LLTCC Face}

To mine coal with the LLTCC mining method in extrathick coal seams, the category of strata control should be extended as well. After the completion of top-coal caving operation, it is not possible for the roof rock to cave and fill in the goaf in a short time. Therefore, the immediate roof will form a cantilever beam, and the main roof will form a stable articulated beam. In other words, a cantilever beamarticulated beam will be formed in a LLTCC face. Generally, the overlying strata does not simply follow the movement from the lower layer to the upper layer. Instead forms various combinations of structures and moves with some laws. Figure 3 shows the structural model of the roof.

A comprehensive analysis shows that in LLTCC Face 8105 , during the large periodic weighting, the movements of upper main roof and lower main roof intensify, and some high energy micro-seismic events occur in upper main roof. During the small periodic weighting, lower main roof fractures frequently, and the low energy micro-seismic event occurs in the lower main roof. Therefore, the periodic fracture of main roof can be regarded as the periodic instability of articulated beam. The unstable lower cantilever beam in the main roof leads to small periodic weighting, and the unstable upper articulated beam in the main roof leads to large periodic weighting. The breakage of the lower main roof results in the breakage of the cantilever beam in the immediate roof and small periodic weighting; the breakage of the upper main roof leads to the breakage of the lower main roof and indirectly prompts the collapse of the cantilever beam in the immediate roof. Since the breakage of the upper main roof prompts the breakage of the lower main roof simultaneously, it has a wide and significant impact. Therefore, a large periodic weighting, in other words, the phenomenon of large and small periodic weighting in the face, is the basic characteristic of roof fracture and its impact on roof hydraulic support. 


\begin{tabular}{|c|c|c|c|c|c|c|}
\hline \multicolumn{7}{|c|}{ Comprehensive borehole histogram of the $3-5 \#$ coal seam at the No. 8105 coalface } \\
\hline \multicolumn{3}{|c|}{ Strata } & \multirow{2}{*}{\begin{tabular}{|c|} 
Histogram \\
$1: 200$ \\
\end{tabular}} & \multirow{2}{*}{ 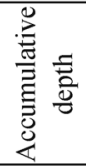 } & \multirow[b]{2}{*}{ Thickness } & \multirow[b]{2}{*}{ Descriptions } \\
\hline 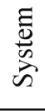 & 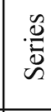 & $\cong$ & & & & \\
\hline \multirow{4}{*}{ : } & \multirow{4}{*}{ 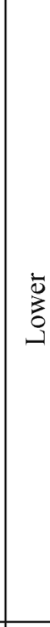 } & \multirow{4}{*}{ 离 } & 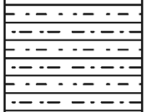 & 66.71 & $\frac{2.46-10.10}{5.37}$ & $\begin{array}{l}\text { Grey white, grey black sandy mudstone; mudstone; locally } \\
\text { lightgrey kaolinite and grey white magmatic rock; mainly } \\
\text { sandy mudstone }\end{array}$ \\
\hline & & & & 61.34 & $\frac{0.36-3.08}{1.78}$ & $\begin{array}{l}\text { Coal: (Shan } 4 \# \text { ), half bright type, oil, asphalt gloss, locally } \\
\text { silicification, containing } 1-2 \text { plies partings, parting lithologiesare } \\
\text { black mudstone, carbonaceous mudstone }\end{array}$ \\
\hline & & & 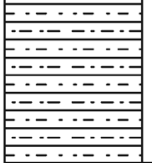 & 59.56 & $\frac{0.50-2.27}{1.12}$ & $\begin{array}{l}\text { Grey black carbonaceous mudstone, mudstone, sandy mudstone, } \\
\text { kaoliniticmudstone, grey white magmatic interbedding, high } \\
\text { carbonaceous content, flate fracture surface, brittle, containing } \\
\text { large amount of plant tem and leave fossil }\end{array}$ \\
\hline & & & 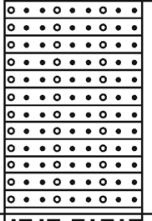 & 58.44 & $\frac{10.46-21.73}{15.67}$ & $\begin{array}{l}\text { Brown, grey, grey white, dark grey fine sandstone, medium } \\
\text { coarse sandstone, coarse sandstone, coarse sandstone with } \\
\text { gravel, siltstone, and sandy mudstonealternated, mainly } \\
\text { composed of quartz, feldspar and other minerals, } \\
\text { cementedtightly, hard core. Diameter of gravel is greater than } \\
2 \mathrm{~mm} \text {, good separation and roundness degree }\end{array}$ \\
\hline \multirow{7}{*}{ 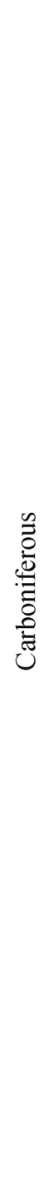 } & \multirow{7}{*}{$\frac{\grave{\varpi}}{2}$} & \multirow{7}{*}{ 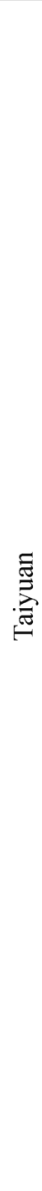 } & 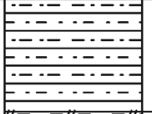 & 42.77 & $\frac{0.60-7.21}{3.17}$ & $\begin{array}{l}\text { Grey, grey white, dark grey, variegation siltstone, fine } \\
\text { sandstone, medium coarse sandstone, coarse sandstone, } \\
\text { gravel alternated }\end{array}$ \\
\hline & & & 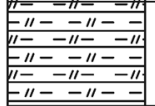 & 39.60 & $\frac{0.10-9.34}{2.97}$ & $\begin{array}{l}\text { Grey black sandy mudstone, mudstone, grey blue magmatic } \\
\text { rock silicified coal alternated, locally dark grey siltstone, } \\
\text { uniformed structure }\end{array}$ \\
\hline & & & & 36.68 & $\frac{0.15-2.10}{1.33}$ & $\begin{array}{l}\text { Coal: (2\#), dull, powdery, locally metamorphic, mainly } \\
\text { silicified, } 1-2 \text { pliespartings in the middle, black carbonaceous } \\
\text { mudstone, sandy mudstone }\end{array}$ \\
\hline & & & 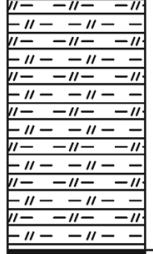 & 35.30 & $\frac{2.57-6.43}{4.49}$ & $\begin{array}{l}\text { Yellow white, grey white, grey blue magmatic rock, grey black } \\
\text { carbonaceous mudstone, dark grey mudstone, black silicified } \\
\text { coal alternated; the structure of magmatic rock is semi- } \\
\text { crystalline, unstable occurrence, and uneven thickness; the } \\
\text { structure of silicified coal is loose; carbonaceous mudstone } \\
\text { contains plant stemand leave fossil, smooth, brittle, dirty, } \\
\text { fragile }\end{array}$ \\
\hline & & & & 24.80 & $\frac{12.18-18.17}{14.81}$ & $\begin{array}{l}\text { Coal: (3-5\#), black, half bright type, dull, powdery and bulk } \\
\text { structure, total seamthickness } 12.18-18.17 \mathrm{~m} \text {, average } 14.81 \mathrm{~m} \text {, } \\
\text { usable thickness is } 10.17-15.43 \mathrm{~m} \text {, average } 13.16 \mathrm{~m}, 4-14 \\
\text { plies partings, total thickness of partings is } 0.56-3.89 \mathrm{~m} \text {, } \\
\text { average } 1.75 \mathrm{~m} \text {, single parting thickness is } 0.05-0.83 \mathrm{~m}, \\
\text { partinglithologies are blackkaolinite, grey brown kaolinite } \\
\text { mudstone, grey black carbonaceous mudstone, mudstone, } \\
\text { sandy mudstone, locally dark grey siltstone }\end{array}$ \\
\hline & & & 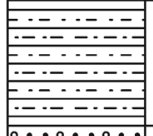 & 9.99 & $\frac{1.50-9.18}{4.87}$ & $\begin{array}{l}\text { Grey brown, light grey kaolinite mudstone, bulk, contains } \\
\text { carbonization body and cinder, locally dark grey sandy } \\
\text { mudstone in southern part, bulk, tight, even, plant stem and } \\
\text { leave fossil }\end{array}$ \\
\hline & & & 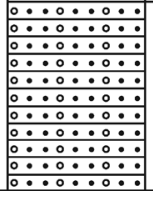 & 5.12 & $\frac{4.22-11.69}{5.12}$ & $\begin{array}{l}\text { Grey white, light grey fine sandstone, medium sandstone, } \\
\text { coarse sandstone, coarse sandstone with gravel, composed of } \\
\text { mainly quartz and feldspar, hypo-edge angle, less roundness, } \\
\text { medium separation degree, locally grey white gravel, mainly } \\
\text { quartz with chert, } 15 \mathrm{~mm} \text { diameter, hard }\end{array}$ \\
\hline
\end{tabular}

Figure 1. Coal rock strata histogram in Face 8105.

\subsection{Roof control technology for the LLTCC Face}

In regard to characteristics of special deformation damage of surrounding rock at the LLTCC Face 8105, effects of surrounding rock on support structure, support intensity, and shift capability should be taken into full consideration, in order to improve the adoptability of support to production method and increase the responding ability of 


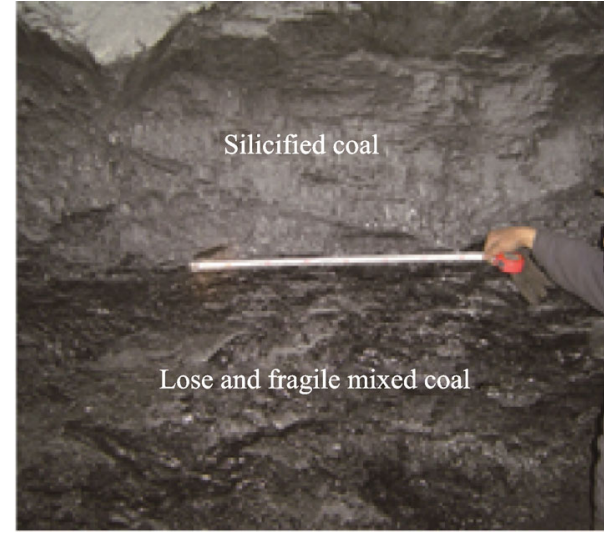

Figure 2. Coal rock strata structure of roof at Face 8105.

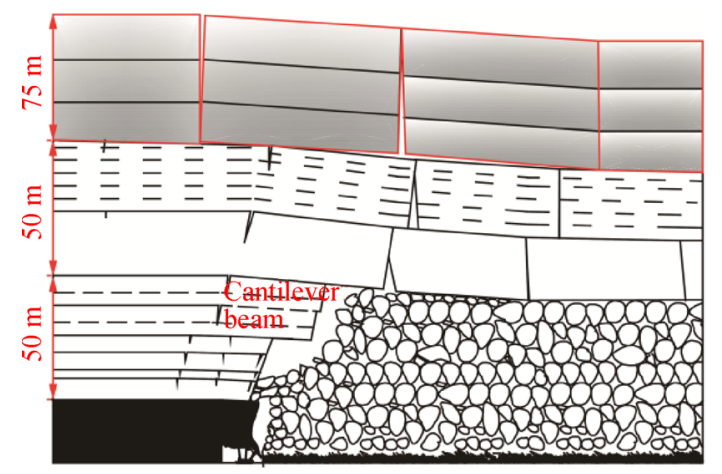

Figure 3. Roof structure model in LLTCC Face.

support to sudden roof pressure. As the support and rock coupling based on 3D dynamic parameter design started from the roof movement, a simulation was conducted to simulate the transfer of fracture, subsidence, crash and the caving of roof into the pressure, torque, deformation and shift speed of the support. Under various conditions, support working resistance, support type and control parameters were dynamically determined to satisfy the requirements of roof movement and effective support on the roof. Considering the characteristics of the protective wall and floor, the patterns and parameters of the auxiliary components for wall protection and bottom lift were determined. The advantages of the method proposed can be stated as: the dynamic characteristics of surrounding rock are fully considered during dynamic interaction between supports and the surrounding rock; the variation of roof subsidence and fracture is transferred to the support in the forms of pressure, torque and constraints. Hydraulic support responds in terms of forms and characteristic parameters, and the responding results are fed back to rock in the forms of support resistance force and torque. Therefore, the roof caving and the distribution of stress and strain can be controlled. The ZF15000/28/52 hydraulic

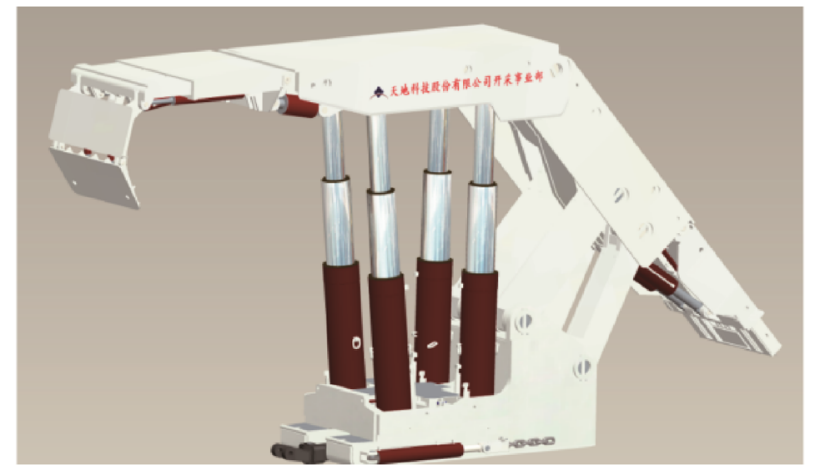

Figure 4. ZF15000/28/52 top-coal caving hydraulic support with a large supporting height.

support was optimized (Figure 4) based on analysis above. Its working resistance was greater than $15,000 \mathrm{kN}$. The site industrial test demonstrated that the support could provide good control on surrounding rock.

\subsection{Technologies for wall spalling controlling in LLTCC Face}

As the cutting height is large and the exposed wall is high, the technology for preventing spalling is a key technology. At different stages of non-periodical weighting and periodical weighting, and with differences in mining height, advance speed and distance from the support tip to the wall, the spalling depth and spalling ratio were different in the LLTCC Face (Yan, 2008). To understand the spalling law in the LLTCC Face, the wall spalling were analyzed under different conditions, such as different mining heights, different advance rates, different distances from the support tip to the wall, and different weighting stages.

With numerical simulation method, the horizontal displacements of the wall with mining heights of $3.5 \mathrm{~m}$, $4.5 \mathrm{~m}, 5.0 \mathrm{~m}$ and $5.5 \mathrm{~m}$ were simulated and the results are shown in Figure 5.

Figure 5 shows that the peak horizontal displacement increases with the increase of mining height. Considering that the normal mining height is $4.0-4.5 \mathrm{~m}$, and the point of peak horizontal displacement to floor is approximately 2.5 $3.0 \mathrm{~m}$, and the proper height of the wall guard plate of support should be $1.5 \mathrm{~m}$. Based on the simulation results, the second level wall guard plate was installed on a high reliable extendable beam and an articulated front beam to prevent the spalling of the coal wall. Its structure is shown in Figure 6.

The face advance speed also significantly affects the wall spalling. Research results in Face 8105 demonstrates that with the increase of face advance speed, there is a reduction of damage area around the wall, and a reduction of wall horizontal displacement. In other words, the spalling of wall is reduced. It is therefore suggested that the face 


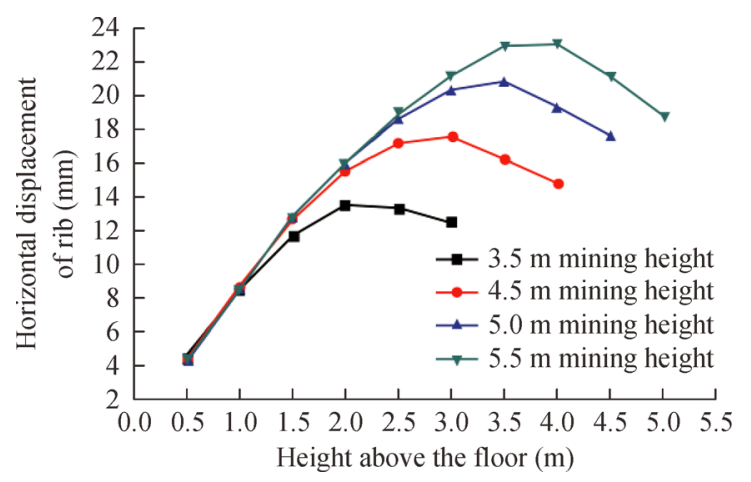

Figure 5. Horizontal displacements of wall with different mining heights.

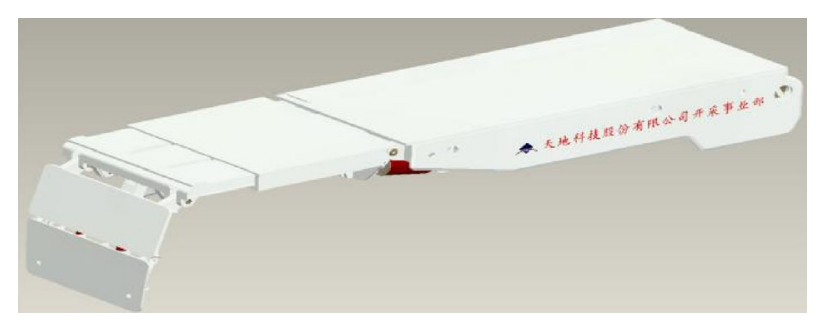

Figure 6. Structure of the second level wall guard plate installed on the extendable beam.

advance speed should be properly increased to reduce the exposure time and wall spalling. Nevertheless, the effectiveness of wall spalling control was limited by increasing face advance speed. With a large amount of field observation, the effect of increasing face advance speed on wall spalling has been analyzed. If the advance speed is too high, the wall spalling might increase.

With the distance from support tip to wall increasing, the peak abutment pressure in front of the face decreases. Subsequently, the displacement at support tip increases significantly, and the damage zone in front of the face also increases, which might lead to a significant spalling. Undoubtedly, the distance from the support tip to the coal wall should be reduced appropriately. The wall should be timely supported.

Coal cutting height, face advance speed and distance from support tip to wall are three factors that have obvious effects on wall spalling. Their weighted effects could be ordered as coal cutting height $>$ face advance speed $>$ distance from support tip to wall.

The effect on wall spalling from the caving and displacement of the top-coal and the roof has regular patterns. The wall spalling clearly appears before ground pressure starts, increases to a maximum with ground pressure, and decreases to a minimum after ground pressure disappears. During periodical weighting, the spalling ratio of the wall increases to an average of $24.58 \%$. With a low face advance speed, the effect on wall spalling would be substantial from periodical weighting. Therefore, the maintenance of the wall should be enhanced during periodical weighting in order to mitigate the wall spalling.

The seriousness of wall spalling varies at different positions. Wall spalling is the most serious in the middle part of the face, less serious in the lower part of the face and better in the upper part of the face.

Based on the data of LLTCC Face 8105, the position of peak abutment pressure in front of the face was within 10 $25 \mathrm{~m}$, the relative stress concentration coefficient $\mathrm{k}$ was 1.3-6.5 during the peak, and the average was 2.13. From the $10-25 \mathrm{~m}$ zone in front of the face to the wall was the stress release zone, and the effected zone by abutment pressure was $80 \mathrm{~m}$.

A comprehensive spalling control technology to determine face advance speed, increase initial support power, and improve the support capacity for wall protection was developed, after characteristics of wall spalling in LLTCC Face under different conditions, including mining height, coalface advance speed, distance from support tip to coal wall, ground pressure, and different positions of the face, had been analyzed

By comparison of wall spalling with the neighboring Face8104, it can be concluded that: (1) geological and mining conditions in Face 8104 and 8105 were similar, and the cutting heights were $3.5 \mathrm{~m}$ and $4.5 \mathrm{~m}$, respectively. Therefore, the comparison of wall spalling characteristics between the two faces was clearly feasible; (2) according to the statistical analysis of the observation results of nonperiodical weighting, the average wall spalling ratio was $33.08 \%$ and the spalling depth varied from $0.2 \mathrm{~m}$ to $0.3 \mathrm{~m}$ in Face 8104; the average spalling ratio was $22.06 \%$ and the spalling depth varied from $0.18 \mathrm{~m}$ to $0.25 \mathrm{~m}$ in Face 8105; (3) during periodical weighting, the spalling ratio was $36.18 \%$ in Face 8104 , and $29.16 \%$ in Face 8105; (4) based on such statistical analysis, the spalling depth and length were the largest in the middle of Face 8104 and 8105; (5) compared with the spalling ratio in Face 8104, that in Face 8105 was $33 \%$ less, and the spalling depth was also $50 \mathrm{~mm}$ less than that in Face 8104 . Therefore, it can be concluded that the new technology has effectively overcome the problem of wall spalling in LLTCC Face 8105.

\section{Technologies of highly efficient top-coal caving method for LLTCC mining}

\subsection{Proper top-coal step distance}

It is important to select a proper top-coal step distance to improve coal recovery and reduce the percentage of waste. If the step distance is too vast, top-coals might be caved into the goaf and the coal will be lost. If the step distance is too small, the refuse might be mixed with coals and caved into the discharge window, resulting in poor quality coal 
and even loss of coal. The factors for determining the step distance include the thickness of top-coals, the discharge window length of support, the center height of discharge window and the cutting depth of shearers. The principal for determining the step distance is to fracture and loosen topcoals from within the discharged coal, increase top-coal recovery and reduce the percentage of waste. In addition, the proper step distance should be matched with the coal mining process, forming an integer relation with shearer's cutting depth.

The step distance must be greater than the length of discharge window to avoid mixing the refuse with coal. The small step distance might result in mixing the refuse in the goaf with caved top-coal. The vast step distance might result in losses of top-coal. A proper step distance will maintain the mixture of top-coal with refuse and top-coal losses in tolerance limits. In LLTCC Face, the space for top-coal fracturing becomes larger due to the increase in mining height, and effects of ground pressure on top-coal fracture become greater. With effects of ground pressure, the top-coal will be fractured and broken thoroughly. The top-coal fragment becomes smaller and has a better flowability.

Step distance is a key parameter of the LLTCC process as it can significantly affect the flowability of coal and refuse. Figure 7 shows the flow of coal and refuse in different step distance. The boundary of coal and refuse before top-coal discharge is regarded as the starting line of coal discharge. On the other hand, the boundary of coal and refuse after top-coal discharge is viewed as the finishing line of coal discharge. Three step distances were tested, including one cutting and one coal caving, two cuttings and one coal caving, and three cuttings and one coal caving. In the process of support shift and coal caving, the boundary of coal and refuse was moved forward and maintained in the same shape. With the increase of step distance, the distance between the starting line and the finishing line also increased.

As shown in Figure 7, with increased step distance of top-coal, there were some variations in the boundary shape of coal and refuse before and after top-coal caving. In other words, the initial caving point of top-coal shifted forward, the distance between start line and finish line of top-coal caving increased with the increase of the step distance. This indicated that the amount of coal discharge at each discharge circle increased with the increase of the step distance. However, the amount of coal discharge and the discharge effect obtained from numerical simulation is not proportional to the step distance.

There are three kinds of coal and refuse mixtures near the discharge window of support after top-coal caving with different step distance:

(1) When the step distance is small, the refuse in the goaf reaches the discharge window earlier than the top-coal does, and the discharged coal mixes with refuse. Before

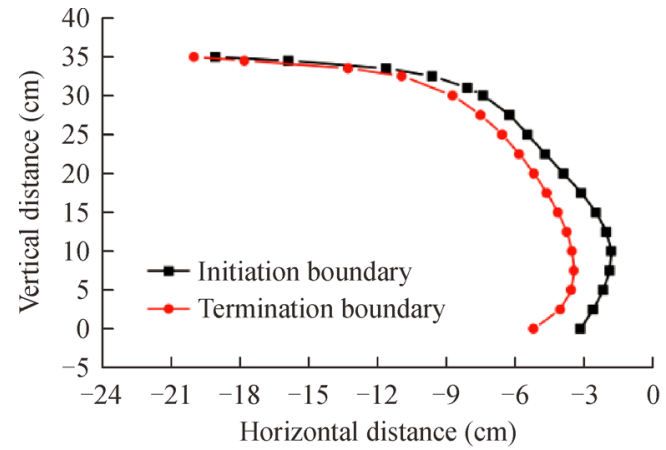

(a) One cutting and one drawing

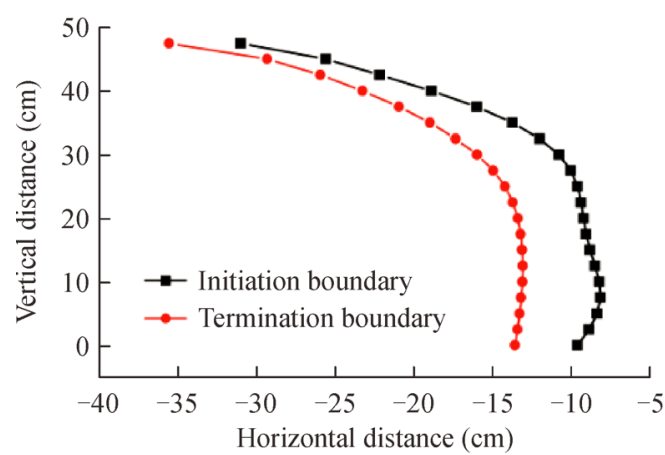

(b) Two cutting and one drawing

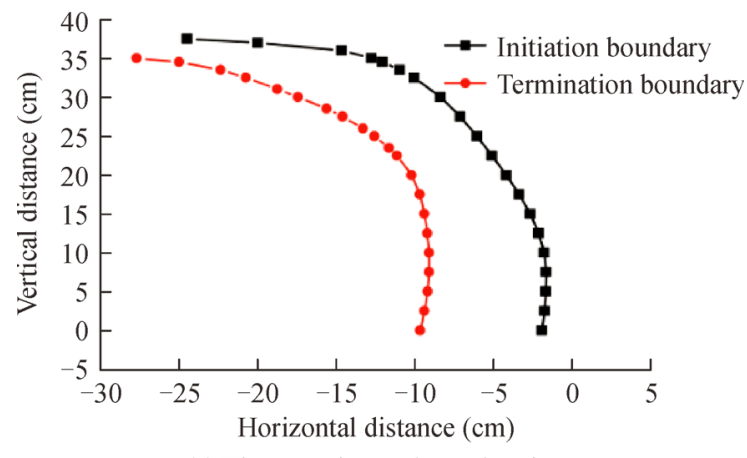

(c) Three cutting and one drawing

Figure 7. Boundary lines between coal and refuse with different step distance.

coal discharge, the boundary between coal and refuse near the discharge window is beyond the lower boundary of the tail beam. Therefore, the part of middle to top-coal is unable to be discharged due to the enclosure of refuse and the tail beam. In this case, the refuse might enter the discharge window from the bottom of the window, and increase the percentage of refuse in the coal caved.

(2) With proper top-coal step distance when discharging coal at the beginning, the refuse in the goaf and top-coal will reach the discharge window of the support at the same time. Before coal discharging, the boundary between coal and refuse is behind the lower boundary of the tail beam, thus the horizontal shift of refuse in the goaf is small. In the process of top-coal caving and discharge, coal can smoothly reach the discharge window. While the lower 
and middle coal is caved, the refuse above the coal seam is caved as well, thus producing some mixture of coal and refuse during the discharge of the upper layer of top-coal. The mixture refuse is mainly from the roof above the seam and it enters the discharge window when the top-coal is being discharged.

(3) If the step distance is too large, at the beginning of coal discharge, the top-coal caved would reach the discharge window earlier than the refuse in the goaf. Before coal discharge, the boundary between coal and refuse is obviously behind the lower boundary of the tail beam, and the refuse in the goaf cannot reach the discharge window. For a LLTCC operation, the angle of the shield beam increases, so does the height of the discharge window. During coal discharge, the top-coal above the discharge window can be discharged quickly and the refuse above the top-coal also caves quickly. In this case, the coal and refuse in the goaf near the discharge window with natural repose angle cannot flow toward the discharge window and thus cannot be discharged. Therefore, coal will be lost and recovery will be low.

Figure 8 shows the forms of remaining top-coal with different step distance. As shown in the figures, the one cutting one caving method (step distance is $0.8 \mathrm{~m}$ ) can achieve high top-coal recovery.

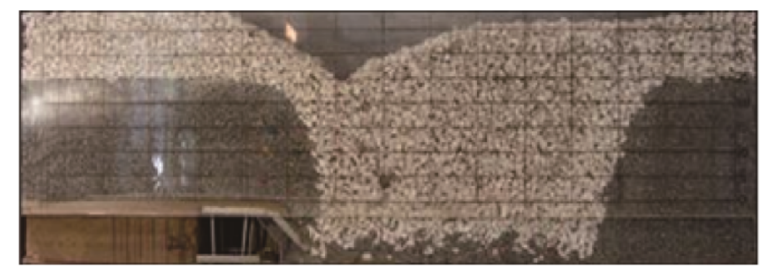

(a) One cutting and one drawing (drawing interval $0.8 \mathrm{~m}$ )

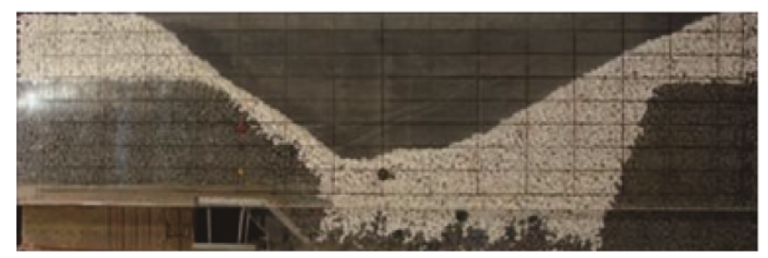

(b) Two cutting and one drawing (drawing interval $1.6 \mathrm{~m}$ )

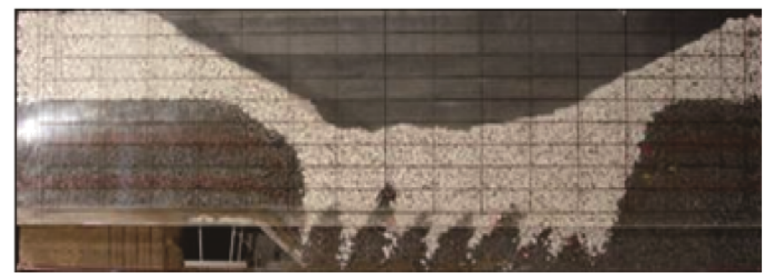

(c) Three cutting and one drawing (drawing interval $2.4 \mathrm{~m}$ )

Figure 8. Forms of remaining top-coals with different step distance.

\subsection{Proper top-coal caving method}

Top-coal discharge method means a combination of sequence of coal discharge, timing of coal discharge at each discharge window, quantity of coal discharge, and the number of discharge windows opened simultaneously along the face. The sequence of coal discharge can be categorized as sequential coal discharge and alternated coal discharge. The timing of coal discharge at each discharge window can be categorized as single, double and multiple coal discharges. The number of coal discharge windows opened simultaneously can be categorized as single window discharge and multiple window discharge. The number of simultaneously opened discharge windows can be categorized as single coal discharge and multiple coal discharge. The quantity of coal discharge can be categorized as equal quantity and non-equal quantity. It is hard to manage equal or non-equal coal discharge in operation, but single or multiple coal discharge can be managed manually. However, the coal discharge method is mainly based on the sequence of coal discharge and the timing of coal discharge at each discharge window. There are four caving methods, including single coal discharge, single sequence coal discharge, multiple coal discharge and multiple sequence coal discharge. Since different coal seams have different geological conditions with different cavabilities, different coal discharge methods should be used. The recovery of top-coal differs accordingly.

Based on the theory of 3D top-coal caving, a numerical simulation was conducted to simulate the top-coal caving and discharge with geological parameters of seams and the technical parameters of hydraulic supports in Tashan Coal Mine. In addition, the simulated loose thickness of the topcoal was $10.5-11.17 \mathrm{~m}$, and the simulated cutting heights were $4 \mathrm{~m}, 4.5 \mathrm{~m}$ and $5 \mathrm{~m}$ respectively. The top-coal caving and discharge operation was simulated respectively with the method of single coal discharge, single sequence coal discharge and multiple sequence coal discharge. The simulation results showed that the single-time sequence multiple windows coal discharge had the lowest recovery of coal caving and discharge, and the multiple-times sequence multiple windows had the highest recovery of coal discharge. To increase recovery of top-coal, the method of multiple-time sequence multiple window coal discharge was selected for the LLTCC operation in Face 8105 of Tashan Coal Mine. Good results were made as expected.

4.3 Discharge structures with high efficiency and high recovery

In addition to step distance and discharge method, the discharge structures also affect top-coal recovery. Studies on previous coal discharge structures reveal the following problems:

(1) The front link bar of previous LTCC supports was a double link bar, and the rear link bar was a single link bar. The rear bar was fixed in the middle of the support base, 
blocking the operator's sight and making it difficult to observe the effects of top-coal caving and discharge.

(2) There was no passage from the front to the rear of the support. Since the rear link bar was fixed in the middle of the support base, operators could not go through two supports from the front to the rear of the support. The only way was to go to the rear of the support via the face end, which was difficult from the perspectives of safety and maintenance.

(3) The coal discharge structure of the tail beam-sliding plate was easily jammed and hard to slide. If it did not slide back, the sliding plate would occasionally cut the chain of the rear scraper conveyor when the tail beam swung.

To solve the fore mentioned problems and optimize the support structure, a new type of coal discharge structure was designed with double front rear link bars, a middle passage and an observation window for coal discharge. In addition, the high efficient and high recovery coal discharge structure had strong disturbance capacity.

The optimized four link bar on support, the shield beam and the base were re-designed to meet the requirements of support movement and limited positions. A new type of coal discharge structure was developed with new double front and rear link bars, a middle passage, and an observation window, as shown in Figure 9.

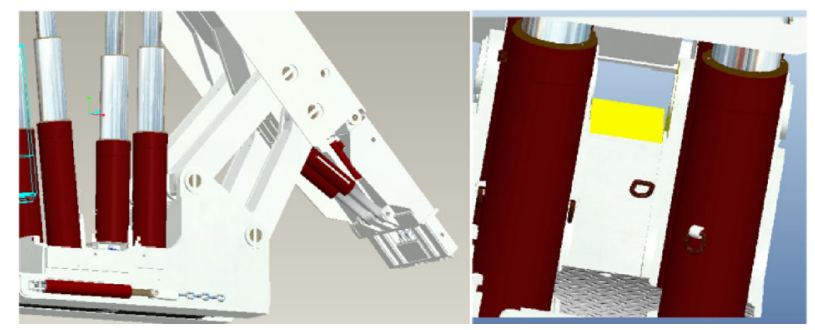

Figure 9. Large passage in the middle of support.

Ground pressure could cause fracturing and caving of top-coal. Coal could have different hardness. During topcoal discharge, the increase of large coals will form a balanced arch above the support discharge window and block the coal. A high efficient and high recovery coal discharge structure was therefore developed with powerful disturbance capacity. Two jacks with cylinder diameter $\backslash$ of $\Phi 180 \mathrm{~mm}$ were installed on the tail beam for operation. The force of a single jack could be adjusted to $1,000 \mathrm{kN}(P=39$ $\mathrm{MPa}$ ) and 2,000 kN. To increase the disturbance to topcoals, the upswing of the tail beam could reach $19.5^{\circ}$ to crush top-coals, and the down swing could reach $41^{\circ}$ to put forward the coal flow. During top-coal discharge, the tail beam was swung continuously to disturb the top-coals and to achieve a highly efficient and high recovery coal discharge. The coal discharge structure broke the base of the balanced arch, or crushed the large block of coals to ensure continuous operation of top-coal discharge.

\section{Gas control for LLTCC face}

\subsection{Characteristics of gas emission and distribution in LLTCC face}

The gas emission and distribution in the LLTCC face have four distinctive characteristics:

(1) Low gas reserves, and high gas emission. Influenced by large thickness of coal seam and high mining intensity, the LLTCC mining operation in extra-thick coal seam features low gas reserve and high absolute gas emission. In Seam 3-5, the original gas pressure was only 0.14$0.17 \mathrm{MPa}$, and the gas content in coal seam was 1.6$1.97 \mathrm{~m}^{3} / \mathrm{t}$, with the average of only $1.78 \mathrm{~m}^{3} / \mathrm{t}$. Yet, the absolute gas emission in the face exceeded $40 \mathrm{~m}^{3} / \mathrm{min}$, with the highest up to $65 \mathrm{~m}^{3} / \mathrm{min}$.

(2) Unbalanced gas emission. The sources of gas emission in LLTCC Face in Tashan Coal Mine can be divided into three parts. i) gas on the top of the goaf, including gas from the upper adjacent layer; ii) gas in the bottom part of the goaf including gas from the lower adjacent layer; iii) gas from coal mining and caving operations in the airflow of the face. Gas emission from the fore mentioned sources would be affected by the ground pressure of the face, the collapse of main roof and the caving of top-coal. The unbalanced and uneven emission coefficient might reach 1.8 .

(3) Large gas emission in the goaf. Local gas emission in the goaf showed that emissions often exceeded gas limit in the area between the 110th support and the upper corner of the face. In the window of top-coal caving and the gap between supports, the measured gas concentration reached $2 \%-3 \%$, sometimes even higher. In the $U$ type ventilation face, gas concentration far exceeded gas limit in the upper corner of the face. Without taking any measures in the upper corner, gas concentration often exceeded $5 \% .90 \%$ of gas emission was from the $10 \%$ of the rear of the face. Special gas control measures must be taken accordingly.

(4) The occurrence of gas in the face indicated a nonlinear relationship. Figure 10 shows the gas concentration distributed along the vertical direction and face advance direction in LLTCC Face. Gas concentration distributed in the vertical face and the goaf showed an increasing trend from the bottom to the top, increasing $2.3 \%$ every $5 \mathrm{~m}$. From the rear to internal displacement $32 \mathrm{~m}$, gas distribution showed an increasing trend within the same elevation. From the support in face to the deep goaf, and within the range of $200 \mathrm{~m}$, the gas concentration showed a ladder-type distribution. Within the range of 0-60 $\mathrm{m}$ from the support to the goaf, gas concentration increased from $1.5 \%$ to $2.8 \%$. Within the range of 60 $160 \mathrm{~m}$ in the goaf, gas concentration increased from $3.6 \%$ to $4.6 \%$. Within the range of $160-200 \mathrm{~m}$ in the goaf, gas concentration increased from $5.7 \%$ to $6.1 \%$, and basically coincided with the three spontaneous combustion zones. 


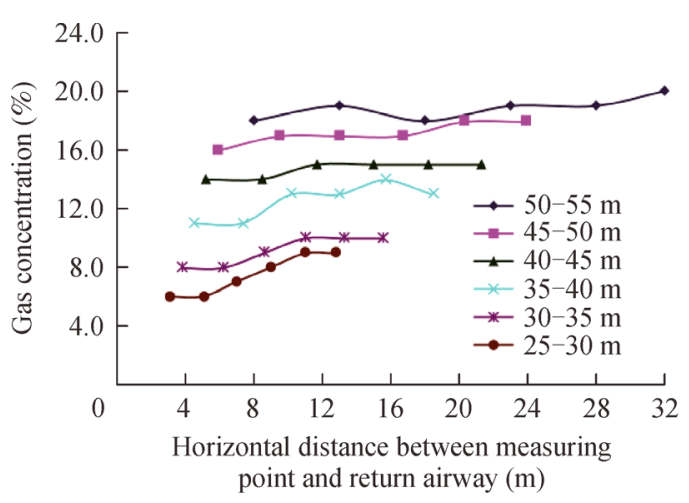

(a) Along the direction of roof height

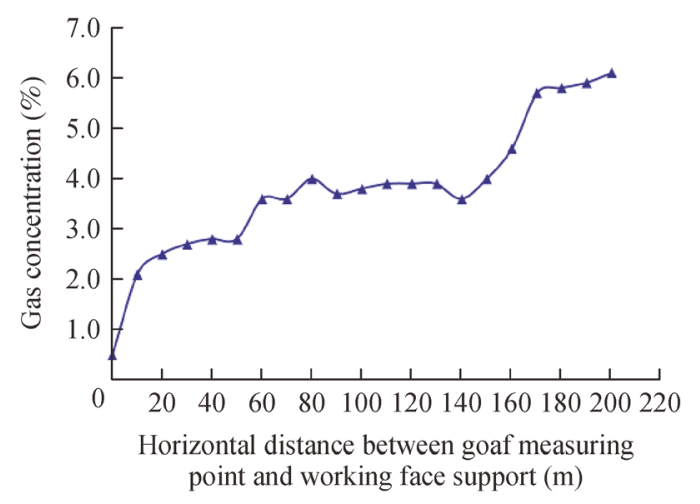

(b) Along the direction of face advance

Figure 10. Gas concentration distributed along the directions of vertical height in the goaf and face advance.

\subsection{Gas control technologies for LLTCC Face}

Based on the characteristics of gas occurrence, the comprehensive gas control technology for LLTCC Face is developed to improve gas drainage in the goaf, optimize ventilation system in the face and open an in-roof gas drainage roadway. A three-step integrated project was carried out accordingly. The first step was to open a gas drainage roadway in the roof and actively drain the gas in the goaf. The second step was to block the gas by seals in the upper and lower corners and induce and dilute the gas by wind curtains to control gas limit in the upper corner of the face at the early stage of mining. The third step was to establish a large flow gas drainage system, including highposition pre-buried vertical tube, upper corner drainage tube and optimized face ventilation system. Gas drainage and mining operations in Face 8105 in Tashan Coal Mine is shown in Figure 11.

Site monitoring results showed that gas drainage technology in roof combined with other drainage operations in Face LLTCC could significantly reduce gas concentration at the return air corner of the goaf, control gas emission from the goaf to the face, help splitting gas flow, and reduce gas concentration in the goaf. The effect of preventing gas from accumulation in the upper corner of

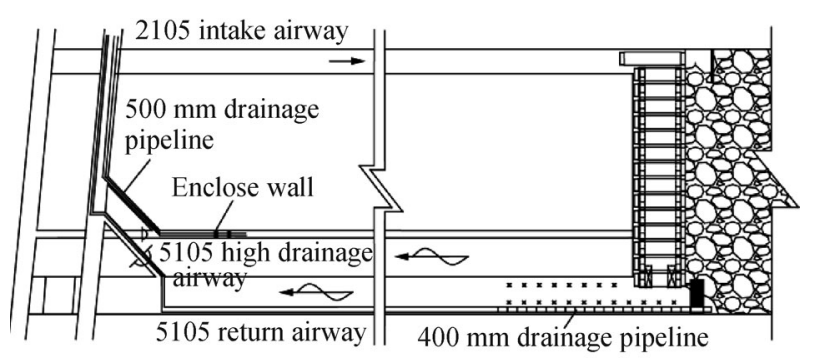

Figure 11. Gas drainage in Face 8105.

the face was apparent. The drainage rate in the goaf reached $40 \%$ of total gas emitted from the goaf, achieving no gas over-limit, and securing a safe mining operation.

\section{Results of underground mine test}

Key technologies for LLTCC mining method, including coal extraction, strata control, high efficient top-coal caving and safety security, were tested for the first time in LLTCC Face 8105 in Tashan Coal Mine. The face went into trial operation in September 2010 and went into normal production in October 2010. From October 2010 to December 2011, the industrial test was conducted in the face.

From October 2010 to December 2011, the average operation rate of equipment was $92.1 \%$, average work efficiency was $364.5 \mathrm{t}$ per manpower, coal recovery in the face reached $88.9 \%$, increasing $5.9 \%$ compared with that in Face 8104.

On November 9, 2010, Face 8105 was connected with the in-roof high drainage roadway. With the gradual increase of gas emission, gas concentrations in the upper corner, in the face and in the return airway gradually became stable. The gas drainage rate of the goaf reached $40 \%$ of the total gas emitted in the goaf, achieving no gas over-limit in the face.

In 2011, the face achieved an average monthly coal production of $0.9076 \mathrm{Mt}$, with the highest $1.035 \mathrm{Mt}$. For the first time, with the Chinese developed technologies and Chinese made mining equipment, the accumulative annual coal production in Face 8105 reached 10.849 Mtpa, exceeding the aimed 10 Mtpa coal production in LLTCC Face.

\section{Conclusions}

(1) The fully-mechanized top-coal caving technologies for extra-thick coal seams with large mining height and the theories of effective strata control have been successfully developed. In front of the wall, the movement of top-coal and roof shows horizontal compressive deformation under 
abutment pressure. At the rear of the wall, the roof movement mainly indicates a fracture subsidence movement, and the movement of top-coal indicates a vertical movement caused by fracture and subsidence of the roof. In front of the wall, the horizontal deformation speed of topcoal and roof caused by face abutment pressure is much smaller than the vertical subsidence speed of top-coal and roof after fracturing in the rear of the wall.

(2) A complete set of equipment with capacity of 10 Mtpa for the LLTCC Face has been developed. Hydraulic supports with double front link bars and double rear link bars, two-level wall protection devices with extendable beam of high reliability have been developed. Experts proposed the comprehensive wall spalling control technologies in relation to the speed control of face advance, the improvement of support setting force and the protection capacity of wall spalling.

(3) Based on the theory of 3D coal caving, studies on effects of different step distance and different top-coal caving methods on top-coal recovery have been carried out, and the new idea of one cutting one caving, multiple sequence and multiple openings was put forward. With the optimized structure of the hydraulic support, a powerful disturbance discharge device of high efficiency and recovery has been developed.

(4) Featured with low gas reserves and high gas emission in the LLTCC Face, a comprehensive gas control technology for Face 8105 by the in-roof drainage roadway has been developed. Gas drainage rate in the goaf reached more than $40 \%$ of the total gas emitted in the goaf, achieving no gas over-limit and securing safe mining operations.

(5) Key technologies for LLTCC Face have been successfully applied in Face 8105 in Tashan Coal Mine. During the test, the average equipment operation rate reached $92.1 \%$. The coal recovery rate reached $88.9 \%$, improving 5.9\% compared with that in Face 8104. In 2011, the cumulative coal production in the test face reached 10.849 Mtpa, exceeding the aimed 10 Mtpa in LLTCC Face, achieving localization of mining equipment made in China, and leading the technological development of extrathick coal seam mining in the world.

\section{References}

Li, M., Liu, K., \& Zeng, M. (2006). Full seam cutting and caving mining technology in and its development prospect. Coal Mining Technology, 11(5), 28-29, 43.

Lu, X., Zhao, X., Xu, X., \& Xue, S. (2006). Kit technique research about fully-mechanized coal winning equipment. Coal, 15, 6-7.

Mao, D., \& Yao, J. (2010). Adaptability of long wall top-coal caving with high cutting height. Journal of China Coal Society, 35, 1837-1841.

Qian, M., \& Shi, P. (2003). Coal mine pressure and roof control. Beijing: China Coal Industry Publishing House.

Wang, G. (2010). Top-caving powered support and fully-mechanized caving technology.Beijing: China Coal Industry Publishing House.

Wang, J. (2006). Present status and development tendency of fullymechanized coal mining technology and equipment with high cutting height in China. Coal Science and Technology, 34, 4-7.

Wang, J. (2013). Key technology for fully-mechanized top-coal caving with large mining height in extra-thick coal seam. Journal of China Coal Society, 38, 2089-2098.

Yan, S. (2008). Research on side and roof falling mechanism and control approaches in caving mining with large mining height. Coal Mining Technology, 13, 5-8. 